\title{
Una investigación sobre la Función de la Escritura en la Clínica Psicoanalítica
}

\author{
An investigation on the Function \\ of Writing in the Psychoanalytic Clinic
}

\author{
Mg. Ivonne M. Serena \\ Directora: Dra. Sara Vassallo
}

\section{RESUMEN}

La tesis de Maestría titulada "La Función de la Escritura en la Clínica Psicoanalítica. Especificidad Clínica: el síntoma como trama entre significante y letra"despliegala pregunta por el lugar de la escritura en psicoanálisis, el cual, se presenta como enigmático porque puede ser tanto soporte explicativo de múltiples aspectos teóricos como articulador intersticial de las elaboraciones que habitan el límite mismo del concepto en psicoanálisis.

Este impacto controversial de la noción de escritura nos motivó a asumir una posición problematizadora sobre las interpelaciones que nos acerca el trabajo clínico. A partir de abordar esta estructura hipotética en un trabajo exhaustivo de interlocución con las elaboraciones freudianas y lacanianas produjimos una serie de premisas tentativas sobre los límites que configuran el campo nocional de la escritura $y$, en consecuencia, el itinerario de articulaciones con otros conceptos clínicos visibilizados a través del hilo conductor del síntoma pues evidencia a la propia estructuración psíquica.

\begin{abstract}
The Master's thesis entitled "The Function of Writing in the Psychoanalytic Clinic. Clinical Specificity: the symptom as a plot between signifier and letter "displays the question of the place of writing in psychoanalysis, which is presented as enigmatic because it can be both explanatory support of multiple theoretical aspects and interstitial articulator of the elaborations that inhabit the very limit of the concept in psychoanalysis.

This controversial impact of the notion of writing motivated us to assume a problematizing position on the interpellations that bring us closer to clinical work.

From approaching this hypothetical structure in an exhaustive work of interlocution with the Freudian and Lacanian elaborations, we produced a series of tentative premises about the limits that make up the notional field of writing and, consequently, the itinerary of articulations with other visualized concepts through the conductive thread of the symptom, in as much, evidence to the own psychic structuring.
\end{abstract}


Palabras Clave

Psicoanálisis - Escritura - Síntoma Significante - Letra
KeY Words

Psychoanalysis - Writing - Sympton Signifier - Letter 
ENTRE EL CONCEPTO LÍMITE Y EL LÍMITE DEL CONCEPTO EN PSICOANÁLISIS

Dejemos que nuestro investigador conquiste tempranamente la experiencia de que todo saber es fragmentario y que en cada uno de sus grados quedasiempre un resto $\sin$ solucionar.

S. Freud, 1909

La presente tesis de Maestría surge de una investigación realizada entre los años 2012 y 2017, en el marco de la Maestría de Psicoanálisis que funciona en la Facultad de Psicología de la Universidad Nacional de Rosario. Su formulación integra inquietudes en relación a esta temática surgidas ya desde la formación de grado y en diversos espacios de lectura en instituciones psicoanalíticas. Sin embargo, la instancia de posgrado permitió situar las principales coordenadas de la misma a partir de relevar en las teorizaciones freudianas y lacanianas un método de trabajo surgido desde elaboraciones fragmentarias que habilitó un campo de interlocución discursivo para problematizarla.De este modo, su producción conceptual no sólo se circunscribió a la exploración de textos teóricos sino que se delineó también en el intercambio con los docentes de los distintos seminarios, en la bibliografía compartida con los compañeros de cursado e incluso desde algunas preguntas surgidas en las elaboraciones clínicas del análisis personal y los espacios de supervisión que se conjugaronen sus orientaciones principales.

A tal efecto, los aportes del paradigma indiciario de Carlo Ginzburg nos permitió abordar el lugar de la escritura en psicoanálisis a partir de campos de tensión donde conceptualizar ya no es detectar las caracteristicas sobresalientes de un objeto o situación, sino "examinar los detalles más omitibles" (Ginzburg, 2004:p.70) y los "indicios que a la mayoría le resultan imperceptibles” (Ginzburg, 2004:p.72). En este sentido, nuestra modalidad de trabajo fue desagregar los substratos que sostienen a los conceptos principales situados en los escritos freudianos y lacanianos para luego rescatar que huellas han dejado en la elaboración del saber psicoanalítico y, consecuentemente, que direcciones abren para pensar el campo clínico en nuestro tiempo contemporáneo.

Desde esta perspectiva, consideramos que en psicoanálisis, el modo de narrar nuestra clínica está atravesado por lo paradojal que habita en los conceptos analíticos, porque si bien su incidencia es determinante en la estructuración de la experiencia, al mismo tiempo, a los conceptos se les escapa lo que quieren aprehender. En su misma configuración están atravesados, como dice Freud por esas"ideas nebulosas iniciales apenas aprehensibles, que esperará aclarar o podrá cambiar por otras en el curso de su desarrollo"(Freud, 1914, p.2019), por lo cual, suponen lo aprehensible como fuerza directriz que trama y destrama afectaciones. En este sentido, la construcción de conceptos analíticos surge de la huella de una alteración en el saber -es decir, algo que el saber produce pero desconoce- que retorna como su propia perturbación y, en eso que lo excede, ubicamos su relación con la verdad.

En este sentido, Freud nos orienta al señalar que la "deformación, no sólo significa alterar una forma sino, también, desplazar algo a otro lugar, trasladarlo" (Freud, 1934-1939, p.3264) Encontramos 
ejemplos de ello tanto en la formación teórica como en la formación del síntoma, puesto que la teoría también da cuenta de esas deformaciones de un texto donde "hallaremos oculto en alguna parte, lo suprimido y lo negado, aunque allí se encontrará modificado y separado de su conexo, de modo que no siempre será fácil reconocerlo"(Freud, 1934-1939, p.3265)

En consecuencia sostenemos que entre el concepto límite y el límite del concepto hay en psicoanálisis un interregno que, bajo la modalidad de un entre paréntesis, opera sobre un fondo de opacidad. Es su rasgo constitutivo que los conceptos estén implicados en el trayecto mismo que los genera. Claramente, podemos aseverar, entonces, que en psicoanálisis los campos de investigación y de reflexión no se hallan disociados y que el proceso de producción complica al sujeto que investiga en aquello que lo causa.

La tesis despliega en varias puntuaciones que ese tiempo interregno no plantea un pasaje progresivo de un término al otro, sino que es el campo de tensiones el que engendra las condiciones de posibilidad para la construcción de los conceptos analíticos. Porque, fundamentalmente, la problemática gira en torno a un vacío y a un excedente que busca inscripción. Se pone en juego en este punto lo imposible de la sexualidad y la muerte que se transmiten por la vía del equívoco, y ese es nuestro campo específico.

Por lo tanto, es en el relato analítico donde se relevan los obstáculos que reinventan a nuestro trabajo clínico a partir de un saber fragmentario. Sus expresiones, a través de las formaciones del inconsciente y el síntoma, ensayan lecturas de un potencial actual que porta las marcas del mundo pulsional. La escritura ensayisticase deja tomar por estos rasgos para que, a través del encadenamiento de argumentos, el síntoma hable desde ese punto irreductible que habita a la estructura psíquica. Es en la argamasa misma de esas letras, entonces, desde donde "el ensayo psicoanalítico trabaja los conceptos, los tensa, los fragmenta queriendo argumentar y transmitir lo que de nuestra práctica -su asunto- se pierde." (Ruinsztejn,2001,p.137)

Afirmamos, entonces, que es la praxis misma del inconsciente con la eficacia del acto la que, en su elaboración, contiene lo que ex-siste al concepto. Tenemos aquí la función de la negación en psicoanálisis, que preserva algo al precio de transformarlo en otra cosa, y por ello su aprehensión es "sólo mediante un salto, un paso al límite, que cobra forma acabada realizándose". (Lacan,1964, p.27) Su consecuencia: ningún concepto puede decirlo todo.

Desde esta perspectiva, es condición del discurso psicoanalítico inventar un lector, construyendo un lugar que antes no existía. Este es un rasgo común en Freud y Lacan, quienes, cada vez, rozándose con lo impensable, producían, en acto, una desestabilización de las referencias que condujo al germen interno de los conceptos analíticos, es decir, aquello que los devuelve a la trama abierta de la Otredad.

\section{Escritura y Huella Freudiana}

El resplandor es coronamiento del primer rasgo y de lo que lo borra. Lo he dicho: es por su conjunción que se hace sujeto, más porque se marcan allí dos tiempos. Es menester pues que se distinga allí la tachadura. 
El lugar de la escritura en psicoanálisis se presenta como enigmático, porque puede ser tanto soporte explicativo de múltiples aspectos teóricos como articulador intersticial de las elaboraciones que habitan el límite mismo del concepto en psicoanálisis.

Este impacto controversial de la noción de escritura nos motivó a asumir una posición problematizadora sobre las interpelaciones que nos acerca el trabajo clínico. A partir de esta estructura hipotética elaboramos una serie de premisas tentativas sobre los límites que configuran el campo nocional de la escritura y, en consecuencia, el itinerario de articulaciones con otros conceptos clínicos visibilizados a través del hilo conductor del síntoma pues evidencia a la propia estructuración psíquica.

En este sentido, sus múltiples abordajes teóricos -lingüísticos, literarios, filosóficos, lógicos, topológicos- y su condición diaspórica en la trama conceptual del psicoanálisis requirió de una orientación inicial para conjeturar su lugar en el discurso psicoanalítico. Fue la figura del Onomaturgo (Rabant,1993, p.1) -el hacedor de nombres- desde donde constituimos una vía de acceso para desplegar la densidad figurativa que propone la escritura psíquica de lo inconsciente. (Koop,1996,p.12)

De este modo, esa primera condición enigmática de la escritura se abrió a una instancia donde el acto de nominación devino marca de una pluralidad de escrituras que atraviesan tanto a la práctica clínica como a su producción teórica. El trayecto recorrido por las obras de Freud y Lacan nos permite afirmar que, en su carácter disruptivo, la escritura funda un cuerpo conceptual, constituido por una red de fragmentos que evocan un territorio de fuga originaria.

La experiencia del lenguaje, que atraviesa de lleno el acto analítico, implica la invención de un lector -con su ética de lectura- y el empuje escritural del acontecimiento sintomático. Una orientación principal en esta tesis postula que, para leer el síntoma en clave de escritura, será preciso acceder a las instancias de estructuración psíquica, por las cuales el sujeto y el significante quedan enlazados en la emergencia de la letra, función límite que instituye algo allí donde antes no había nada.

Una de nuestras conclusiones más importante al respecto es que el síntoma no es simplemente el resultado de un juego de fuerzas en conflicto, sino el acto que produce estructura psíquica, en el sentido más riguroso del término.

Consideramosque Lacan introduce una profunda subversión de la noción freudiana de síntoma al articularlo, no ya con el discurso, sino con la escritura por la vía de la letra. Ello implica, al mismo tiempo, la reformulación de la función paterna y su pluralización en los Nombres del Padre. En esta secuencia de lectura, la integración del sinthome a la problemática del nudo como suplencia determina cambios que inciden profundamente en la práctica clínica, en el estatuto de la interpretación y ensus efectos analíticos.

En función a esta premisa, sostenemos que si hay una especificidad de la noción de escritura en la clínica psicoanalítica, está en función de concebir a lo originario bajo tachadura. (Derrida, 1989,p.3) A través de la diferenciación entre lo originario, lo primario y lo unario, introduce lo intersticial de ese salto que inaugura y signa lo insoluble de un vacío. 
Ese vacío inicial e inaprensible será la insistencia de una marca que actualiza su construcción según los problemas clínicos convocantes. Hemos intentado asir este proceso a partir de un conjunto de figuraciones que nos permitió poner en serie aquellos elementos diaspóricos a los que hicimos referencia al comienzo. En tal sentido, propusimos una suerte de contigüidad entre las figuraciones del palimpsesto y la borradura y, a partir de ello, especificamos una noción de escritura devenida de la Niederschrift o inscripción psíquica, en tanto constituye el principio rector de la estructuración del aparato psíquico.

Nuestro punto de ilegibilidad sitúa a esta originalidad fundada en la diferencia como una incógnita en permanente desplazamiento. Empuje escritural que traza, borra, inscribe esa ausencia de origen de donde se sirga lo irrepresentable. Se trata de algo que sólo alcanzamos bajo la forma de una "escritura palimpséstica, de pérdida y transformación acumulativa" (Koop,1996,p.102) gracias a la función significante. Entonces, "el onomaturgo pasa a ser un sirgador de palabras.”(Rabant, 1993,p.278)

En este sentido, la noción de escritura empieza a delinear un espacio de inscripción a partir de un corte que no tiene representación original. En el disloque de percepciones, la traducción opera, a nivel primario, la pérdida de la identidad, y transfiere una orientación del sentido que pulsa en el corazón mismo de la repetición. "Escritura que incluye el tiempo como un factor de escritura", (Rabant, 1993, p.278)sostenida en un diferimiento en el cual la traducción como síncopa de temporalidad introduce lo fallido. Es allí donde está el acervo de la obra freudiana definida como Niederschrift o inscripción psíquica. Es en la no simultaneidad del registro donde encontramos la posibilidad de sus desplazamientos, sustituciones y borramientos que se confrontan a la pérdida.

Desde esta perspectiva, inauguramos nuestro recorrido con la problematización del concepto freudiano de huella psíquica. En la primera parte de la tesis consideramos de capital importancia la lectura realizada por Jacques Derrida, en torno a los textos comprendidos entre el "Proyecto de una Psicología para neurólogos” (Freud,1895) y “El Block Maravilloso" (Freud,1925). En ese marco de elaboración freudiana, el autor sitúa toda la problemática del abrirse-paso hacia "una metafórica de la huella escrita”. Así, Derrida reconoce, ya en los primeros bocetos de aparato, las vías de constitución de la "escritura psíquica"

Coincidente con el inicio de siglo, el nacimiento del psicoanálisis adquiere, en realidad, la forma de tres comienzos diferentes para su corpus teórico. Podríamos ubicar el "Proyecto de Psicología” (Freud,1895), como la primera fundación donde se encabalgó una pretensión de aparato psíquico entre la biología y un saber de límites imprecisos que fue erosionando el escenario. Luego con "La Interpretación de los sueños" (Freud,1900) se confirma una fundación lograda, cuyo resultado teórico más importante es la metapsicología freudiana. Y, finalmente, "Más allá del principio del placer" (Freud,1920) reclama un nuevo tiempo escritural, con su deletreo en la instancia originaria, allí donde lo ilegible que lo habita será una "legibilidad [que] está en proceso de parto”. (Soler,1994). De este modo, relevar la lectura de las elaboraciones freudianas sobre lo 
inconsciente promovieron un despliegue de esta conceptualización de huella como una diferencia incapturable, concomitante con una cierta violencia en la apertura y su correspondiente resistencia ante la fractura.

En el "Proyecto de una Psicología para neurólogos”(Freud,1895)se propone un aparato de lenguaje atravesado por esa escritura del abrirse-paso que instituye la lógica del borramiento a partir de esa primera experiencia de satisfacción. Si bien el auxilio ajeno, a través de una acción específica, rescata al hombre de su indefensión primaria lo complica, al mismo tiempo, en esa intrusión que Freud denominó “Complejo del prójimo". A partir de ese prójimo será posible discriminar lo ajeno y lo propio, lo extranjero y lo íntimo, lo inconmensurable -das Ding- y lo conmensurable -la representación-. Como primera exterioridad respecto del Otro y, por lo tanto, primer real de la estructura, es el fundamento de la subjetividad.

De tal modo, situamos en esa escritura del abrirse paso el acto que rompe con la identidad y remite a esa alteridad radical que signa la imposibilidad del encuentro con la Cosa.

Estas marcas indiciarias vuelven a ponerse en escena en la “Carta 52"(Freud, 1887-1902), pues allí la estratificación de la memoria sitúa una densidad libidinal que figura a la escritura por diferimiento. Esta dimensión introduce la problemática particular de lo intraducible que funda un aparato mnémico en el encuentro de la heterogeneidad pulsional y la traza significante. En ese contexto, la noción de intervalo -portadora de las marcas de lo borrado- constituye los bordes pulsionales, que se pierden y conservan cada vez. El tiempo del acontecimiento sintomático, entonces, demarca lo irreductible de una pérdida originaria como condición estructural para la función de la representación.

Sin embargo, es en "La Interpretación de los sueños” (Freud, 1900) donde esta lógica de borramiento adquiere su más alta legibilidad. Ello tiene lugar en una escritura psíquica que, a través del trabajo del sueño, resulta engendradora de elaboraciones significantes, las cuales anudan el deseo a la pulsión mediante una frontera fugitiva. Será luego el relato del sueño el que ejercerá una acción negativa de tachadura sobre ese trabajo de ligazón incesante que emprende la censura.

De este modo, tanto en el sueño como en el síntoma, el aparato formula -mediante la condensación y el desplazamiento- las satisfacciones sustitutivas de un deseo que se actualiza en función de las huellas mnémicas investidas para tal fin. En tal proceso, los deseos inconscientes actualizan los signos perceptuales de la primera experiencia de satisfacción, pero siempre según el retardo con respecto al referente que inscribe la lógica significante.

Es decir, el texto inconsciente ya está tejido por huellas mnémicas que son depósitos de un sentido el cual no ha estado nunca presente y cuyo significado es siempre reconstituido con retardo y a destiempo. En este sentido, la interpretación de los sueños es una lectura y un desciframiento. El mérito analítico reside, pues, en poder deletrear uno a uno los elementos de la significación, de modo tal de investir las palabras en una red escrituraria.

A través de este juego de escrituras, la experiencia inconsciente produce su propia significancia y el sujeto inventa su gramática. Un aspecto que consideramos 
de capital importancia es reconocer en la palabra del soñante una doble vertiente de la letra, que resuena en sus asociaciones en transferencia, allí donde se detiene una significación precipitada al afuera de sentido. Por lo tanto, es a través de la interpretación que Freud hace del sueño una escritura devenida de la instancia de la letra en juego en el inconsciente. A partir de ella, abre un pasaje al saber inconsciente para ese trazo fuera de sentido que la letra evidencia como del orden del goce.

Por medio de esta indeterminación significante que articula la letra, es que la elaboración de la noción del ombligo del sueño señala un estado de escritura en ruinas, que revela la profunda subversión del planteamiento freudiano. Ese lugar en sombras que constituye el Unerkannte -de lo no reconocible,punto de opacidad infranqueable en tanto límite que no tiene palabra-, (Freud, 1900,p.132) es el vórtice donde toda detención devela su raigambre en lo incognoscible que nos ha engendrado como parlêtre y, por lo cual, nos hallamos excluidos de poder dar cuenta de nuestro origen.

En este sentido, nuestro acento de lectura halló continuidad en el agieren freudiano, que inaugura el sentido de la repetición en acto. Efectivamente, en "Más allá del principio de placer"(Freud, 1920),Freud problematiza la repetición como fundadora de la huella desde donde el lenguaje visibiliza su ligazón con la muerte. Al mismo tiempo, la palabra se transmuta en posibilidad de vida.

Desde este punto de vista, el viraje freudiano piensa una escritura atravesada por un territorio de latencias. Allí, la pulsión de muerte opera como una exterioridad interna que erosiona la lógica dualista que habita en las teorizaciones del padre del psicoanálisis. Esto instala un campo cualificado de consecuencias que demarcan el umbral de lo sensible, constitutivo del aparato psíquico y, en cuanto tal, determina el límite al que pueden llegar ciertas funciones psíquicas.

La última formalización del aparato psíquico freudiano -desarrollada en "El Block maravilloso"(Freud, 1925)- elabora, por último, un dispositivo singular que establece una nueva analogía entre el aparato perceptivo y su máquina de escritura. En tal contexto, las huellas producen el espacio de su inscripción, y se dan, al mismo tiempo, el período de su desaparición.

La conclusión parcial de esta primera parte de la tesis afirma que la profunda inmixión entre escritura y huella freudiana reside en esa lógica de borramiento que habita en su trazo como la potencia engendradora de una escritura que, tras su inscripción, desaparece cada vez.

\section{Del DESCIFRAMIENTO SIGNIFICANTE A LA PERTURBACIÓN POÉTICA}

Una escritura es un hacer que da sostén al pensamiento.

Jacques Lacan, 1976

A fin de avanzar en la posibilidad de argumentar esta función de la escritura en la clínica psicoanalítica, desplegamos, en la segunda parte de esta investigación, el trayecto que va desde el desciframiento significante a la perturbación poética.

Partimos de considerar que hay en la conjetura de Lacan sobre la escritura un tiempo interregno que engendra su propio acontecimiento entre el material que servirá para la escritura y el lenguaje cuya 
estructura opera sin que nos percatemos de ello.

En este sentido, el apólogo lacaniano de la huella cifra el advenimiento del sujeto, que se constituye como inconsciente por acción de la negación, en primer término. Luego, bajo la operación de borramiento, surge el significante, traza de un sujeto. Es así como el sujeto y el significante quedan enlazados en la emergencia de la letra. Ella, en su insistencia, excede la razón inconsciente y demarca transformaciones sustanciales para la lógica significante y su imbricación con el goce.

Lacan $(1957$, p.59) en su Seminario 5 retoma el minucioso análisis freudiano de los actos fallidos realizado por Freud en "Psicopatología de la vida cotidiana" (Freud,1901) a partir de un olvido suyo que lo había dejado en suspenso al no lograr disponer del nombre del pintor de los frescos de la catedral de Orvieto: Luca Signorelli.

La lectura analítica de esta formación del inconsciente expone que no hay un sentido oculto o preexistente a descifrar, sino todo un trabajo de producción de sentido a partir de los huecos diseminados en el texto que conciernen al sujeto que los genera. De tal manera, el lenguaje no funciona meramente a nivel nominal, sino que funda lo real entre los sucesivos recortes y direcciones que delinea el significante en su decir siempre a medias. Lacan (196364) en su Seminario 11retoma el trabajo de este olvido del nombre de Signorelli y se plantea la siguiente pregunta:

¿Es posible no ver surgir del texto mismo, e imponerse, no la metáfora, sino la realidad de la desaparición, de la supresión, de la Unterdrückung, paso a las interioridades? [...] Así, el inconsciente se manifiesta siempre como lo que vacila en un corte del sujeto -del que resurge un hallazgo, que Freud asimila al deseo- deseo que situaremos provisionalmente en la metonimia desnuda del discurso en juego en el que el sujeto se sorprende en algún punto inesperado.(p.35)

De este modo si el "El inconsciente es lo evasivo" (Lacan,1963-64, p.40) es, en tanto, el nombre olvidado está en relación con la posibilidad de existencia de un sujeto de la enunciación en el marco de la estructura psíquica.Es, entonces, en esta incompletud radical del saber — la cual queda expuesta por la vía de lo imposible de nombrar- que ese real causa las formaciones del inconsciente mediante palabras que están también ellas mismas heridas de incompletud.

El significante, ante todo significante de la falta del Otro, actúa como garante de la palabra que introducirá una distancia entre significantes. El hallazgo de lo sorpresivo del deseo actualiza esas primeras huellas mnémicas -engendradoras del significante- a través del juego entre las ruinas metonímicas del objeto y los fragmentos significantes que transfieren su potencialidad de sustracción a la simbolización misma. Es, sin más, la huella que causa determinaciones significantes a partir del efecto de borradura la que da cuenta de la existencia del sujeto del inconsciente.

En este sentido, si el lenguaje que determina al inconsciente estructurado "es un lenguaje en medio del cual apareció su escrito" (Lacan, 1971,p.82), ello se debe a que "es en la cadena de significantes donde el sentido insiste, pero ninguno de sus elementos consiste en la significación 
de la que es capaz en el momento mismo". (Lacan, 1966, p.482) Es decir que es en el acto de enunciación donde el deseo, desplegado por la articulación significante, se inscribe a través de la negatividad, y el sujeto produce una invención significante a partir de algo que está ahí para ser leído.

Como se puede apreciar, en su enseñanza, Lacan avanza en una distinción que precisa el deslizamiento del Lenguaje y Lalengua. Nos propone, en consecuencia, un camino inverso al de la articulación significante. Se trata, así, de un acto de inscripción que le da a la letra estatuto de objeto, puesto que está ligada a la idea de sustancia gozante. De este modo, la escritura como "forma latente al lenguaje mismo" (Lacan, 1962, p.77) reside en esacondición a-estructurada de Lalengua que reduce las palabras a los unos de su motérialité ${ }^{1}$ (Lacan, 1975, p.18) inconsciente bañados por el enigma del sexo.

Se produce aquí una transformación radical, que afecta incluso a los efectos simbólicos de la palabra, a partir de este corrimiento del acento del lenguaje a Lalengua. Dicho acento desplaza el peso de la palabra del Otro, articulada en el lenguaje, hacia la lengua del Otro, oída por el niño. Es decir, el sentido se concibe aquí de modo tal que puede continuar desagregándose hasta alcanzar la unaequivocación, justamente, porque entra en cuestión la primariedad de que gozaban el lenguaje y la estructura, los cuales pasan a ser derivados de Lalengua.

La operación de transliteración releva esta función de hacer pasar algo que es intraducible y, en este juego, surge un plus que supera a la operación de traducción. En tal sentido, se expresa la no identidad del significante consigo mismo, a la vez que se explicita la dimensión real de la letra, pues da cuenta de la erosión entre el saber significante y el goce del objeto. $\mathrm{Su}$ resultado directo es la homofonía que realiza un delineo del contorno de esta letra en la palabra, en tanto, el equívoco de la ortografía produce una vacilación del sentido entre lo leído y lo dicho.

Es allí donde Lacan articula que el inconsciente no es otra cosa que el cuerpo de las palabras, ya que "hablan sin saber absolutamente nada lo que dicen" (Lacan, 1977, p.210); muestran, asimismo, su adhesión originaria al goce bajo la forma del blablablá, es decir, esos efectos del lenguaje que denomina hablaje y que se distinguen de la comunicación.

La homofonía es, pues, el rebús de la palabra que precipita, a partir de la letra escrita, una profunda desorganización de la representación. De tal manera, consideramos que al situar este saber que no puede compartirse, en tanto, uno lo sabe pero no es transmisible determina una incompatibilidad con respecto a la idea de transmisión integral, en función de esta radicalización de la diferencia que la teoría lacanianaformaliza.

Comprendemos, de este modo, que lo informe que figura a la escritura es esa letra que ha dejado de ser instancia para devenir astilla, vestigio, rastro, imagen borrada, incógnita. Es decir, la letra es intermitente en su potencia de engendramiento y en la diseminación de su empuje escritural. En este punto, la letra articula la vertiente de goce -grieta corrosiva en el campo simbólico- cuya función en suspenso constituye la argamasa misma del síntoma.

En tal sentido, el síntoma queda definido, entonces, por el goce de una letra del inconsciente que se sitúa en la estructura del lenguaje, pero a partir de un acto de escritura. Es decir, dicha letra viene al lugar 
de la hiancia de la no relación sexual y prefigura la función del límite, diverso, por completo, al orden del discurso.

Justamente en su escrito Lituraterre, Lacan -mediado por la escritura lógica y sus impasses- presenta una nueva formalización de la letra, ya no pensada como el resto del orden significante, sino como el "el borde del agujero en el saber". (Lacan, 1971, p.109) Es decir, que la letra, diferenciada del significante por lo que no representa o sobre lo que no da apariencia, se transforma en el borde que demarca dos estados de lo expresable.

Reconocemos, entonces, el camino abierto por la conceptualización del rasgo unario, que encuentra aquí su campo de resonancias. La tachadura que realiza la escritura de la letra diluye las identificaciones que resultan de la apelación al Otro. Es por ello que Lacan concibe al sujeto en el acto de producción de la letra, independientemente de las atribuciones conferidas por el Otro. Le confiere, por lo mismo, a la letra, el estatuto de objeto artístico que plantea la ex-sistencia real del sujeto como efecto de una escritura. El artista se convierte, de este modo, en un paradigma del analizante.

En último término, nuestro recorrido estuvo dedicado a establecer cuál es la textura literal que determina "el acontecimiento sintomático que trama a la estructura psíquica".(Ritvo, 2014) Circunscribimos allí múltiples aproximaciones teóricas para dar cuenta de la cifra del sujeto que habita en el corazón mismo del síntoma.

Efectivamente, con la elaboración del lazo entre síntoma y función paterna, especificamos las diversas hebras del Nombre del Padre, según los diferentes momentos de producción lacaniana.
Con el trayecto del síntoma al sinthome, pudimos concluir que si en el transcurso de un análisis el sujeto ha desagregado hasta su mínima expresión -es decir, hebra por hebra- el compromiso del que formaba parte para compensar el desfallecimiento de la función paterna, podrá, entonces, acceder a un "Savoir faire ahí con el propio síntoma que implica el fin de análisis". (Lacan, 1977, p.21)

Esta perspectiva nos permitió relevar un aspecto clínico determinante, en tanto el síntoma, al final del análisis, no tendrá más un alcance de sentido, sino que se irá reduciendo, al modo de un lapsus, a un puro encuentro con la contingencia.

Esta apelación a ese límite del lenguaje constituye al sujeto como agente de invención de alguna respuesta al vacío inevitable de su existencia. Es la experiencia analítica la que singulariza una posición subjetiva en los meandros de un saber hacer con eso nombrado "síntoma".

Recapitulando lo anteriormente expuesto, destacamos, sumariamente, la siguiente articulación conceptual como eje vertebral de la presente tesis.

Desde "La juventud de Gide o la letra y el deseo" (Lacan,1958) o "La carta robada"(Lacan,1955) hasta las últimas elucubraciones lacanianas -Libros XXIII y XXIV del Seminario-, quedan enlazados letra y goce, letra y límite del sentido -como opera en el lapsus, el sueño o el síntoma-. Allí, el Nombre-del-Padre y su pluralización quedan ligados, insistimos, a una radicalización de la diferencia entre significante y letra. Su convergencia con las zonas intersticiales de la identificación, el fantasma y el lugar del sujeto en relación con la lógica significante intentan dar cuenta de la cifra del sujeto que habita en el corazón mismo del síntoma. 
Ese itinerario está vinculado, íntimamente, con una nueva lectura del corpus freudiano -de ahí que hayamos dividido nuestro trabajo en dos partes-. La escritura surge, pues, como uno de los significantes lacanianos que, en diferentes niveles y momentos, nombra. Ya sea que lo haga mediante el mecanismo de borramiento señalado en el seminario de "La identificación" (Lacan, 1961-1962) a partir del principio del rasgo unario que constituye al sujeto; ya sea que lo haga como acompañando, a veces de un modo solo metafórico, la lógica del significante y del sujeto afectados por lo Real.

En nuestro trabajo de investigación hemos abierto diferentes ventanas para abordar el significante "escritura" en Lacan diferenciando los diversos pasajes que tal noción supone. Es así que ella nos condujo desde "La instancia de la letra en el inconsciente" (Lacan, 1966) hasta las elaboracionesen el seminario "El Sinthome"(Lacan, 1975-1976); desde el lenguaje hasta "lalengua"; desde el significante hasta la letra; y desde el nombre propio hasta los Nombres-del-Padre -desplegados en las últimas elaboraciones de Lacan-. Todos estos movimientos dan cuenta, desde nuestro punto de vista, de que el lugar de la escritura y la letra estaban ya en germen en la obra lacaniana desde sus primeras formulaciones teóricas.

\section{NotAS AMPLIATORIAS}

1 El Moterialismees es un neologismo lacaniano que resulta de la condensación de la palabra mot \{palabra\} con la palabra matérialisme \{materialismo\} Cita textual: "Es completamente cierto que es en la manera con la cual lalengua ha sido hablada y también oída por tal y cual en su particularidad, que algo a continuación volverá a salir en sueños, en todo tipo de tropiezos, en todo tipo de maneras de decir. Es, si ustedes me permiten emplear por primera vez este término, en este motérialisme que reside la captura del inconsciente - quiero decir lo que hace que cada uno no haya encontrado otras maneras de sustentar lo que recién llamé el síntoma.” (Lacan, 1975, p.18)

\section{REFERENCIAS BibLIOGRÁFICAS}

Allouch, J. (1988). La 'conjetura de Lacan' sobre el origen de la escritura, en Revista Litoral: La instancia de la letra, Córdoba, Argentina, Editorial la Torre abolida.

(1993),Letra por Letra, Buenos Aires, Argentina, Edelp S. A.

Derrida, J. (1989).Freud y la escena de la escrituraen La escritura y la diferencia, Trad. Peñalver, Barcelona, España, Ed. Anthropos.

Cancina, P. (2008). La investigación en Psicoanálisis, Rosario, Argentina, Homo Sapiens. 
Freud, S.(1895). "Proyecto de una Psicología para neurólogos”, enObras completas (Volumen3).Buenos Aires, Argentina, Amorrortu, 1988

(1896). “Carta 52”, Los oríge-nes del Psicoanálisis, en Obras completas (Volumen 20). Buenos Aires, Argentina, López Ballesteros, Ediciones Orbis, 1993

(1900). “La regresión”,La interpretación de los sueños, en Obras completas (Vol 1).Madrid, España, López Ballesteros, Biblioteca Nueva, 1996

(1901). "El trabajo del sueño”,La interpretación de los sueños, en Obras completas (Vol 4). Buenos Aires, Argentina, Amorrortu, 1988.

(1901). "Psicopatología de la vida cotidiana”en Obras completas (Vol 6). Buenos Aires, Argentina, Amorrortu, 1988.

(1914). "Introducción al narcisismo" en Obras completas (Vol 2).Madrid, España, López Ballesteros, Biblioteca Nueva, 1996.

(1914). "Recordar, repetir y reelaborar"en Obras completas (Vol 12). Buenos Aires, Argentina, Amorrortu, 1988.

(1915). “Lo Inconsciente", en Obras completas (Vol 14). Buenos Aires, Argentina, Amorrortu, 1988.

(1916). "Conferencias de introducción al psicoanálisis” en Obras completas (Vol 15). Buenos Aires, Argentina, Amorrortu, 1988.

(1920). “Más allá del Principio del placer"en Obras completas (Volumen 18). Buenos Aires, Argentina, Amorrortu, 1988.

(1925). “La negación”, en Obras completas (Vol 3).Madrid, España,
López Ballesteros, Biblioteca Nueva, 1996.

(1925)."Inhibición, Síntoma y Angustia”, en Obras completas (Vol 20). Buenos Aires, Argentina, Amorrortu, 1988.

(1925).”El Block Maravi-lloso", en Obras completas (Vol 3).Madrid, España, López Ballesteros, Biblioteca Nueva, 1996.

(1934 [1939]).“Moisés y la religión monoteísta: tres ensayos"en Obras completas (Vol 3).Madrid, España, López Ballesteros, Biblioteca Nueva, 1996.

(1938). "Esquema del Psicoanálisis"en Obras completas (Vol 23). Buenos Aires, Argentina, Amorrortu, 1988.

Koop, G. (1996)."Freud: la densidad figurativa”. Rosario, Argentina, Homo Sapiens.

KuRI, C. (2012). "El concepto de representante de la representación: el problema de la representabilidaden Freud y su transcripción en Lacan" en Cuadernos de Metapsicología $\mathrm{N}^{\circ} 3$. Rosario, Argentina, UNR Editora.

Lacan, J. (1955). El Seminario sobre "La Carta Robada”, Escritos.Buenos Aires: Siglo XXI (2002), Vol 1.

(1955). "Función y cam-po de la palabra y el lenguaje en psicoanálisis”, Escritos. Buenos Aires: Siglo XXI(2002), Vol 1.

(1958). "Las formaciones del inconsciente", Lacan. El seminario. Buenos Aires: Paidós ( 2003), Vol 5.

(1959-1960)."La ética del Psicoanálisis”, Lacan. El Seminario. Buenos Aires: Paidós (1992), Vol 7. 
(1960). "Subversión del sujeto y dialéctica del deseo en el inconsciente freudiano"Escritos.Buenos Aires: Siglo XXI (2002), Vol 2.

(1961-1962)."La identifica-ción", Lacan. El Seminario. EFBA (circulación interna), Vol 9.

(1963)."Los nombres del padre", Lacan. El Seminario. Volumen 10 bis, Clase única. Recuperado de www.efbaires.com.ar/files/texts/ TextoOnline_543.pdf

(1963-1964). "Los cuatro conceptos fundamentales". Lacan. El Seminario. Buenos Aires: Paidós (1993), Vol 11.

(1966)."La instancia de la letra en el inconsciente o la razón desde Freud"Escritos. Buenos Aires, Argentina: Siglo XXI (2002), Vol 1.

(1971). "De un Discurso que no fuera de semblante". Lacan. El Seminario.Buenos Aires: Paidós( 2009). Vol 18.

(1972-1973).“Aún”, Lacan. El Seminario.Buenos Aires: Paidós (1992), Vol 20.

(1975-1976)."El Sinthome"

Lacan. El Seminario. Buenos Aires: Paidós (2006). Vol 23.

(1975). "Conferencia en Ginebra sobre el síntoma", Revista Le BlocNotes de la psychanalyse, Bruselas, Volumen 5, pp. 5-23. Recuperado de http://www.ecole-lacanienne.net/

(1976-1977). "L'insu que sait de l'une-bevues'aile a mourre"Lacan. El Seminario.Buenos Aires: Editorial Artefactos( 2012), Vol 24.

"La cosa freudiana o sentido del retorno a Freud en psicoanálisis". Escritos. Buenos Aires: Siglo XXI (2002), Vol 1.
RABANT, C. (2015) "La escritura y la traducción" en Metamorfosis de la Melancolía. Rosario, Argentina, Nube Negra Edicicones.

(1993)."El onomaturgo" en EsquissesPsychanalytiques Lacan, hoy. Buenos Aires, Argentina, Nueva Visión.

Rabaté, J. M.(2007),Lacan literario: La experiencia de la letra. México: Siglo XXI.

Rabinovich, N.(2009). El inconsciente lacaniano, Buenos Aires, Argentina, Letra Viva.

Ritvo, J. B. (2000).“Del mathema a la mathesisuniversalis (y el retorno a la letra)" en Redes de la Letra: Cuerpo y lengua. Buenos Aires, Argentina, Ediciones Legere. (2004). “La huella de Freud, la huella en Freud"en Del Padre. Las políticas de su genealogía, Buenos Aires, Argentina, Letra Viva.

(2014).El síntoma: estructura de la formación o formación de la estructura Rosario, Argentina, Editorial Co-lectora.

SOLER, C.(2007), "Lalengua, traumática", en De un Trauma al Otro. Escuela de Psicoanálisis de los Foros del Campo Lacaniano, Foro Medellín. (1997). "Los nombres de lo real” enEstudios de Psicosomática,(Volumen 3).Buenos Aires, Argentina, Atuel. 


\section{COMO CITAR ESTE ARTÍCULO:}

Serena, I. (2019) Una investigación sobre la Función de la Escritura en la Clínica Psicoanalítica. Reseña de Tesis, en Revista Psicoanálisis en la Universidad $N^{\circ} 3$. Rosario, Argentina. UNR Editora.

\section{IVONne SEREna}

Psicoanalista y Magister en Psicoanálisis por la Facultad de Psicología, Universidad Nacional de Rosario.

Es Docente a cargo del Seminario de Electivo de la Facultad de Psicología denominado Síntomas del Malestar Contemporáneo. El mismo también fue dirigido hacia la Formación de Graduados a través de la Secretaría de Extensión Universitaria de dicha institución.

Se ha desempeñado como Directora, Evaluadora y Jurado de Trabajos Integradores Finales en la formación de Grado. Es Miembro del Cartel "Letra y Escritura en Psicoanálisis" durante el período 20192021 de la EPSF-ROS.

Es Dictante del Seminario - Taller sobre Escritura Académica para docentes e investigadores universitarios. para el Área de Formación y Capacitación docente en COAD.

Es autora de producciones escritas para jornadas, congresos y diversas publicaciones.

Es Miembro del Comité Organizador delCongreso Argentino Latinoamericano de DDHH perteneciente a la Secretaría Derechos Humanos de la U.N.R.

Otros títulos: Lic. Comunicación Social con Especialización en Medios Masivos y Comunicación Institucional por la Facultad de Ciencias Políticas y RRII perteneciente a la U.N.R. 